\title{
New ultrahigh vacuum setup and advanced diagnostic techniques for studying a-Si:H film growth by radical beams
}

\section{Citation for published version (APA):}

Hoefnagels, J. P. M., Langereis, E., van de Sanden, M. C. M., \& Kessels, W. M. M. (2004). New ultrahigh vacuum setup and advanced diagnostic techniques for studying a-Si:H film growth by radical beams. In G. Ganguly, M. Kondo, \& E. A. Schiff (Eds.), Amorphous and nanocrystalline silicon science and technology, 2004, symposium held April 13-16, 2004, San Francisco (pp. 257-262). [A9.24] (Materials Research Society Symposium Proceedings; Vol. 808). Materials Research Society. https://doi.org/10.1557/PROC-808-A9.24

DOI:

10.1557/PROC-808-A9.24

Document status and date:

Published: 01/12/2004

\section{Document Version:}

Accepted manuscript including changes made at the peer-review stage

\section{Please check the document version of this publication:}

- A submitted manuscript is the version of the article upon submission and before peer-review. There can be important differences between the submitted version and the official published version of record. People interested in the research are advised to contact the author for the final version of the publication, or visit the $\mathrm{DOI}$ to the publisher's website.

- The final author version and the galley proof are versions of the publication after peer review.

- The final published version features the final layout of the paper including the volume, issue and page numbers.

Link to publication

\section{General rights}

Copyright and moral rights for the publications made accessible in the public portal are retained by the authors and/or other copyright owners and it is a condition of accessing publications that users recognise and abide by the legal requirements associated with these rights.

- Users may download and print one copy of any publication from the public portal for the purpose of private study or research.

- You may not further distribute the material or use it for any profit-making activity or commercial gain

- You may freely distribute the URL identifying the publication in the public portal.

If the publication is distributed under the terms of Article 25fa of the Dutch Copyright Act, indicated by the "Taverne" license above, please follow below link for the End User Agreement:

www.tue.nl/taverne

Take down policy

If you believe that this document breaches copyright please contact us at:

openaccess@tue.nl

providing details and we will investigate your claim. 


\title{
New ultrahigh vacuum setup and advanced diagnostic techniques for studying a-Si:H film growth by radical beams
}

J.P.M. Hoefnagels, E. Langereis, M.C.M. van de Sanden, and W.M.M. Kessels

Dept. of Applied Physics, Eindhoven University of Technology, P.O. Box 513, 5600 MB Eindhoven, The Netherlands

\begin{abstract}
A new ultrahigh vacuum setup is presented which is designed for studying the surface science aspects of a-Si:H film growth using various advanced optical diagnostic techniques. The setup is equipped with plasma and radical sources which produce well-defined radicals beams such that the a-Si:H deposition process can be mimicked. In this paper the initial experiments with respect to deposition of a-Si:H using a hot wire source and etching of a-Si:H by atomic hydrogen are presented. These processes are monitored by real time spectroscopic ellipsometry and the etch yield of Si by atomic hydrogen is quantified to be $0.005 \pm 0.002 \mathrm{Si}$ atoms per incoming $\mathrm{H}$ atom.
\end{abstract}

\section{INTRODUCTION}

Over the last two decades, the growth mechanism of a-Si:H has widely been studied, even to such an extent that it has become a model system for understanding thin film growth [1,2]. Meanwhile, the investigations have become more advanced and sophisticated although most of the experiments have been carried out under regular, but sometimes rather well-defined operating conditions for a-Si:H deposition [3]. However, to reach the next level of understanding, i.e. insight into the surface reactions at the atomic scale, surface science-like studies under very well-defined and idealized conditions will be required. Such studies can for example be carried out by mimicking a-Si:H film growth using several well-defined radical beams as, e.g., done for Si plasma etching [4] and deposition of hydrogenated amorphous carbon [5]. In this paper, we present a new experimental setup for beam studies of a-Si:H film growth. In the design of this setup, three basic criteria have been taken into account:

1) The substrate, onto which the film is deposited, is the key factor within the setup and should therefore be easily accessible by (optical) diagnostics and the use of different substrate types, materials, and sizes should be possible. The substrate should also remain clean for a sufficiently long time setting strict demands on the level of vacuum reached in the setup.

2) With well-defined radical (and ion) beams it should be possible to mimic film growth under regular deposition conditions and the radical beams should preferentially be mono-radical and accurately quantified in terms of flux. For a-Si:H, radical beams of $\mathrm{SiH}_{3}$ and $\mathrm{H}$ are most appropriate.

3) The growth process needs to be investigated by advanced in situ diagnostics with a clear preference for "all-optical" techniques which are able to monitor film growth in real time. Furthermore, the techniques need to be innovative such that key questions of a-Si:H film growth (e.g., "What is exact role of surface Si dangling bonds?") can be addressed.

In this paper, a setup named GALAPAGOS, which meets these requirements, is presented and some initial experiments to characterize the setup are reported. 


\section{EXPERIMENTAL SETUP}

The setup, schematically illustrated in Fig. 1(a), consists of two chambers with in between a flange which holds the substrate. Both chambers are separately pumped by turbo pumps and the setup is completely ultrahigh vacuum (UHV) compatible. Using only infrared heating lamps, a pressure of $10^{-8}-10^{-9}$ Torr is reached however a pressure of $10^{-10}$ Torr should be reachable after extensive backing. The substrate can be heated radiatively from the backside by a Boralectric ${ }^{T M}$ heater (from RT to $800^{\circ} \mathrm{C}$ ) and the temperature is actively controlled.

For the moment, the setup is equipped with three radical sources. A thermal atomic $\mathrm{H}$ source, based on a heated capillary, is present to produce a well-defined H flux [6]. An electroncyclotron-resonance (ECR) plasma source (TECTRA GmbH, Germany) can be operated in "atom-mode", "low-energy ion mode", and in "hybrid mode" [7] but is currently under development to produce a $\mathrm{SiH}_{3}$ radical beam. Finally, a hot wire of tungsten is present to deposit a-Si:H films at reasonable deposition rate (compared to $\mathrm{SiH}_{3}$ beam) while, when operated on $\mathrm{H}_{2}$, it can also be used for in situ chamber cleaning. All sources are positioned on a linear shift such that the source-substrate distance can be varied. The gases $\mathrm{H}_{2}, \mathrm{D}_{2}, \mathrm{SiH}_{4}, \mathrm{SiD}_{4}, \mathrm{Si}_{2} \mathrm{H}_{6}$, and $\mathrm{Ar}$ can be introduced into the sources or chamber after passing a gas purifier.

As illustrated in Fig. 1(a), the setup has multiple ports for optical access. Spectroscopic ellipsometry can be applied from the front side $\left(70^{\circ}\right.$ port) to monitor film growth in real time in terms of bulk thickness, surface roughness and optical film properties [8]. Infrared spectroscopy can be applied from the backside ( $45^{\circ}$ port) using an attenuated total reflection (ATR) crystal for high sensitivity. This technique can be applied for $\mathrm{H}$-depth profiling and to determine the $\mathrm{H}$ surface coverage of a-Si:H [3,9]. The same optical port will also be used in future studies in which dangling bonds will be probed at subgap energies by applying the evanescent-wave cavity ringdown technique [10,11]. Dangling bonds will also be studied from the front side of the substrate $\left(35^{\circ}\right.$ port) using the surface-specific technique of second harmonic generation (SHG) [12]. Furthermore, gas phase absorption spectroscopy can be applied in front of the substrate and a residual gas analyzer can be used for thermal-programmed desorption studies.

(a)

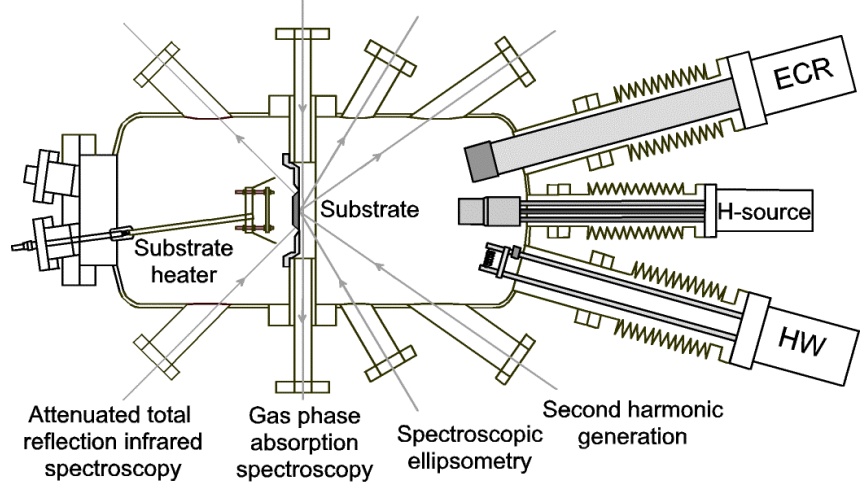

(b)

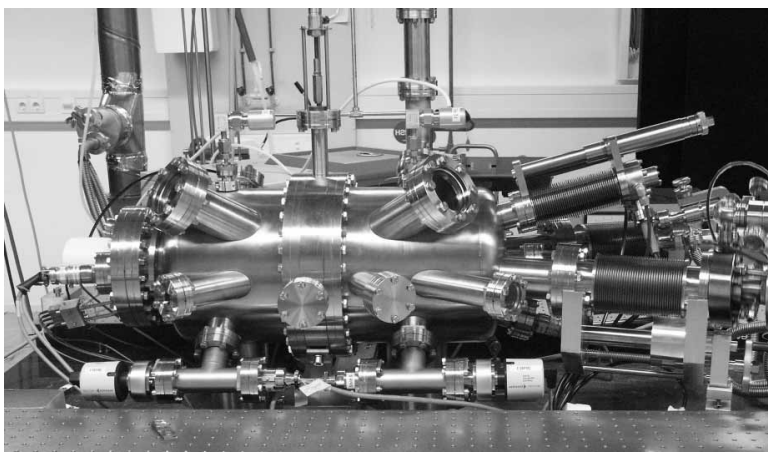

Figure 1. (a) Schematic top view of the UHV setup GALAPAGOS. On the right side the different plasma and radicals sources (ECR: electron cyclotron resonance plasma source; $\mathrm{H}-$ source: thermal atomic H source; HW: hot wire source) are shown. Some diagnostics that can be applied using the different optical ports are indicated. Not shown are: the residual gas analyzer the substrate shutter, and the infrared heating lamps. (b) Picture showing side view of the setup. 


\section{RESULTS}

The first experiments that have been carried out with the GALAPAGOS setup are the deposition of a-Si:H films by the hot wire source and the etching of a-Si:H films by atomic $\mathrm{H}$. The atomic $\mathrm{H}$ is generated by operating the three sources on $\mathrm{H}_{2}$. These experiments have been carried out by using c-Si as a substrate and the processes have been monitored by real time spectroscopic ellipsometry RTSE (Woollam M2000U, 250-1700 nm). The deposition experiments give insight into film properties obtained as well as the deposition rate and the surface roughness evolution of the films. The etching experiments give insight into the source operation and can be used to compare the sources in terms of $\mathrm{H}$ flux produced. Using the calibration data available for the atomic $\mathrm{H}$ source, the etch yield of a-Si:H can be determined.

\section{$\underline{\text { Deposition }}$}

The a-Si:H films have been deposited by the hot wire source from pure $\mathrm{SiH}_{4}$ and at a substrate temperature of $250^{\circ} \mathrm{C}$. The filament current has been set at $11 \mathrm{~A}$ (filament temperature is $2325 \pm 200 \mathrm{~K}$ ), the $\mathrm{SiH}_{4}$ flow at $3 \mathrm{sccm}$, and the pressure in the deposition chamber has been controlled at 8 mTorr. This has resulted in a deposition rate of $78 \AA / \mathrm{min}$. The optical properties and the film thickness have been deduced from the RTSE data obtained at the end of the deposition (film thickness $\sim 2000 \AA$ ) using an optical model and applying the Tauc-Lorentz formalism [13]. The optical model is a simple two layer model (bulk a-Si:H/surface roughness layer) with the common Bruggeman effective medium approximation of $50 \%$ voids and $50 \%$ bulk a-Si:H for the surface roughness. Following the work of Collins and co-workers [8], we have assumed the optical film properties constant during film growth (corroborated by the fact that similar optical properties are obtained at different thicknesses) and the variation of the bulk layer thickness $d_{b}$ and surface layer thickness $d_{s}$ has been deduced. Figure 2 shows the variation of $d_{s}$ with $d_{b}$ as well as the film's dielectric function and the Tauc-Lorentz parameters obtained.

(a)

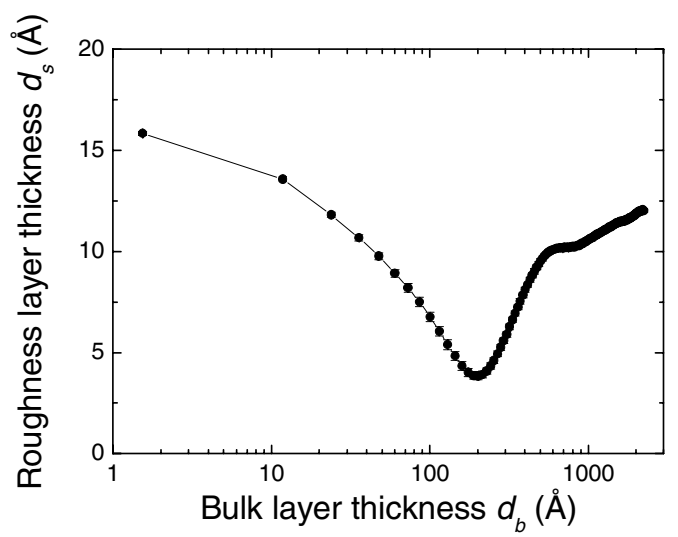

(b)

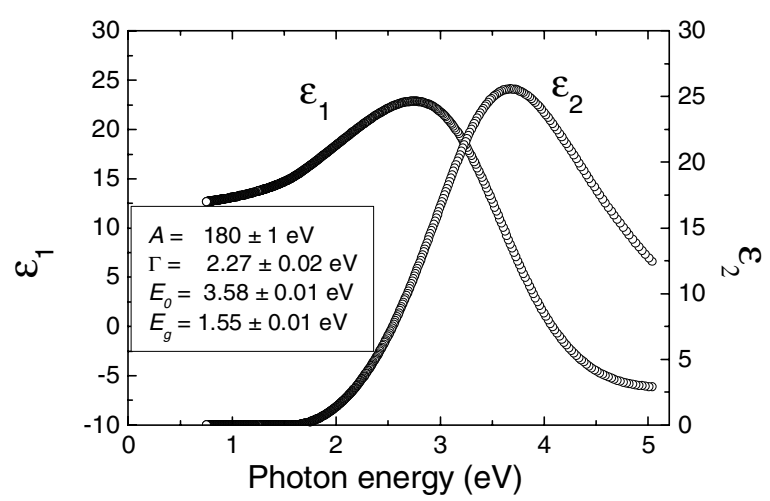

Figure 2. (a) Surface roughness layer thickness vs. bulk layer thickness from RTSE collected during the deposition of an a-Si:H film at a substrate temperature of $250{ }^{\circ} \mathrm{C}$. (b) Corresponding dielectric functions obtained in situ at $250^{\circ} \mathrm{C}$ after deposition of the a-Si:H film. The parameters of the Tauc-Lorentz fit are indicated in the figure. 
Table I: Properties of the a-Si:H films deposited at $250{ }^{\circ} \mathrm{C}$. The analysis techniques are presented in the third column (FTIR = Fourier transform infrared spectroscopy; ERD = elastic recoil detection; RBS = Rutherford Backscattering; $\mathrm{AFM}=$ atomic force microscopy)

\begin{tabular}{||l|l|l||}
\hline Refractive index $n(2 \mathrm{eV})$ & 4.3 & RTSE \\
\hline Extinction coefficient $k(2 \mathrm{eV})$ & 0.177 & RTSE \\
\hline Tauc band gap $E_{\text {Tauc }}$ & $1.67 \mathrm{eV}$ & RTSE \\
\hline Microstructure parameter $R^{*}$ & 0.06 & FTIR \\
\hline H-content [H] & 10.7 at. $\%$ & FTIR \\
\hline H-content $[\mathrm{H}]$ & 11.3 at. $\%$ & ERD \\
\hline Si atomic density $n_{\mathrm{Si}}$ & $5.1 \times 10^{22} \mathrm{~cm}^{-3}$ & ERD/RBS \\
\hline O atomic density $n_{\mathrm{O}}$ & $2.2 \times 10^{16} \mathrm{~cm}^{-3}$ & ERD \\
\hline Surface roughness $w_{r m s}$ & $11 \AA$ & AFM \\
\hline
\end{tabular}

The dielectric function and the Tauc-Lorentz parameters are in good agreement with those reported for a-Si:H in the literature $[8,13]$. Detailed comparison of the data with those reported in Ref. [14] shows that the broadening parameter $\Gamma$ matches best with those for very thin a-Si:H films obtained by $\mathrm{H}_{2}$ diluted $\mathrm{SiH}_{4}$ in an rf plasma. Therefore we have verified that our films are purely amorphous using Raman spectroscopy. The evolution of the surface roughness $d_{s}$ with $d_{b}$ shows also good agreement with the data reported by Collins and co-workers for a-Si:H deposited by an rf plasma at a similar deposition rate [8,14]. In the first $200 \AA, d_{s}$ decreases due to coalescence of the nucleation-induced microstructure and this smoothening effect leads to a minimum roughness $d_{s}=4 \AA$ at a thickness $d_{b}=\sim 200 \AA$. Subsequently, $d_{s}$ increases again due to the amorphous-to-amorphous $(\mathrm{a} \rightarrow \mathrm{a})$ roughening transition [8]. The position of this $\mathrm{a} \rightarrow \mathrm{a}$ transition is in good agreement with the data reported for the rf plasma while our initial decrease in roughness $\Delta d_{s}$ is bigger. The final roughness at a film thickness of $2000 \AA$ is somewhat smaller and shows good agreement with the rms surface roughness deduced from AFM data (see Table I). Furthermore, for a film thickness $d_{b}>700 \AA$, the roughness can be analyzed in terms of the dynamic scaling coefficient $\beta$ (i.e., $d_{s} \sim d_{b}{ }^{\beta}$ ). This analysis leads to a $\beta=0.16$ [15].

Table I summarizes the film properties obtained from the ellipsometry data as well as information on the $\mathrm{H}$ content and bonding, film atomic densities, and the surface roughness. The $\mathrm{H}$ content is typical for a film deposited at $250{ }^{\circ} \mathrm{C}$ and the two values obtained by the two diagnostics show good agreement. The $\mathrm{Si}$ atomic density of the film is fairly high and the oxygen contamination is very low [16]. The latter can probably be attributed to the relatively low base pressure $\left(10^{-9}\right.$ Torr $)$ during the deposition experiments and the use of gas purifiers.

It can therefore be concluded that a-Si:H with good (structural) film properties can be obtained by the hot wire source present in the UHV setup and that the film properties and growth process is similar to those reported in the literature.

\section{Etching}

Films of a-Si:H deposited under the aforementioned conditions, have been etched at a substrate temperature of $85^{\circ} \mathrm{C}$ by operating the three sources on pure $\mathrm{H}_{2}$. Under this condition, the sources produce atomic $\mathrm{H}$. From the etch rates obtained, the three sources can be compared to each other in terms of $\mathrm{H}$ flux produced.

First the atomic $\mathrm{H}$ source has been used to etch a-Si:H. The source has been operated at a $\mathrm{H}_{2}$ flow of $0.43 \mathrm{sccm}$ (pressure is $7 \times 10^{-3} \mathrm{mTorr}$ ) and the temperature of the hot capillary has 


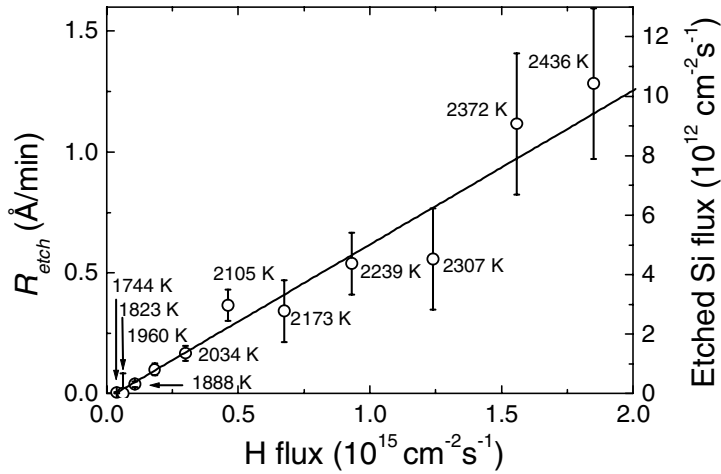

Figure 3. Etch rate $R_{\text {etch }}$ as a function of the $\mathrm{H}$ flux produced by the atomic $\mathrm{H}$ source. The $\mathrm{H}$ flux, varied by varying the capillary temperature, has been calibrated by the manufacturer of the source. On the right axis the etched Si flux is displayed.

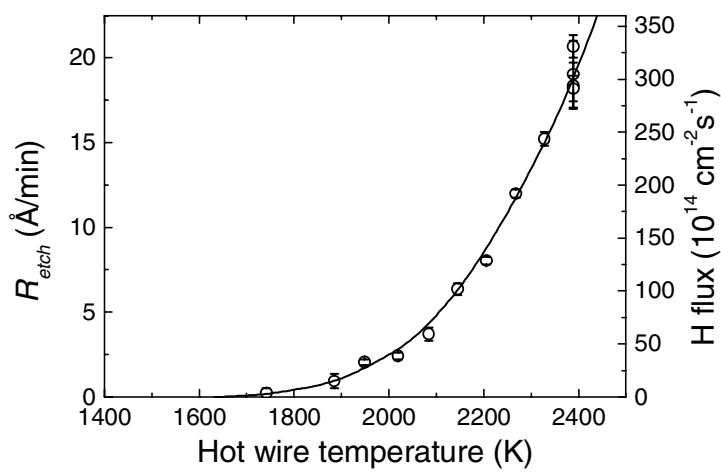

Figure 4. Etch rate $R_{\text {etch }}$ as a function of the hot wire temperature (pressure is 120 mTorr, distance hot wire-substrate is $6.8 \mathrm{~cm}$ ). On the right axis the $\mathrm{H}$ flux is displayed as deduced from the atomic $\mathrm{H}$ source data shown in Fig. 3.

been varied (see Fig. 3). The distance between source and substrate was set at $15.4 \mathrm{~cm}$. Because the atomic $\mathrm{H}$ flux at the substrate position is known from a calibration of the source by the manufacturer [6], the etch rate has been plotted in Fig. 3 as a function of the $\mathrm{H}$ flux. For the analysis of the RTSE data of the etching experiments, a three-layer model had to be assumed. Compared to the deposition experiment, an additional layer below the surface roughness layer is present to account for $\mathrm{H}$ in-diffusion into the a-Si:H film [17]. This leads to an $\mathrm{H}$ interaction layer which saturates at a thickness of $115 \AA$ (at $85^{\circ} \mathrm{C}$ ) when reaching steady state etching conditions. When applying this model, a linear relation between etch rate and atomic $\mathrm{H}$ flux is observed in Fig. 3. This relationship can be used to quantify the atomic $\mathrm{H}$ flux from the other two sources, but it can also be used to determine the etch yield of $\mathrm{H}$. The etch rate can be converted into "etched Si flux" when using the information on the Si atomic density of the film (Fig. 3). Subsequently, from the slope in Fig. 3 we can deduce an etch yield of $0.005 \pm 0.002 \mathrm{Si}$ atom per incoming $\mathrm{H}$ atom. The accuracy of this etch yield is mainly determined by the systematic uncertainty in the calibration data of the source [6].

For the ECR plasma source and hot wire source, similar etching experiments have been carried out. A typical result is given in Fig. 4 for the hot wire source. Using the relation between etch rate and atomic $\mathrm{H}$ flux as shown in Fig. 3 (for other data sets we have evidence that $R_{\text {etch }}$ is linear in $\mathrm{H}$ flux for a $\mathrm{H}$ flux up to $\sim 10^{16} \mathrm{~cm}^{-2} \mathrm{~s}^{-1}$ ), we can deduce the atomic $\mathrm{H}$ flux produced by the hot wire source at the position of the substrate. In Table II, the range of atomic $\mathrm{H}$ flux that can be obtained by the three sources (by varying the operating conditions and the distance between source and substrate, etc.) is summarized.

Table II. Ranges of $\mathrm{H}$ fluxes that can be obtained by the three sources when operated on $\mathrm{H}_{2}$.

\begin{tabular}{|l|l|l||}
\hline & $\begin{array}{c}\text { Range H flux } \\
\left(\mathbf{c m}^{-2} \mathbf{s}^{-1}\right)\end{array}$ & \multicolumn{1}{|c|}{ Variable operating conditions } \\
\hline Atomic H source & $10^{12}-10^{16}$ & $\mathrm{H}_{2}$ flow, capillary temperature, pressure, distance \\
\hline Hot wire radical source & $10^{13}-3 \times 10^{16}$ & $\mathrm{H}_{2}$ flow, hot wire temperature, pressure, distance \\
\hline ECR plasma source & $10^{13}-10^{15}$ & $\mathrm{H}_{2}$ flow, microwave power, pressure, distance \\
\hline
\end{tabular}




\section{CONCLUSION}

A new setup has been presented for well-defined beam studies to reveal the surface science aspects of a-Si:H film growth. Initial experiments with respect to deposition of a-Si:H and $\mathrm{H}-$ induced etching of a-Si:H have been carried out to characterize the setup. Next, experiments will be carried out by advanced diagnostics such as second harmonic generation, attenuated total reflection infrared spectroscopy, and evanescent-wave cavity ringdown spectroscopy, etc.

\section{ACKNOWLEDGMENTS}

The authors acknowledge W.M. Arnold Bik (Utrecht University) for the ERD/RBS analysis, H. Donker (Delft University of Technology) for the Raman spectroscopy measurements, and M.J.F. van de Sande, J.F.C. Jansen, A.B.M. Hüsken, and H.M.M. de Jong for their skilful technical assistance. The central workshop "GTD" and in particular J.G.M. Moerel and P.F.M. Aendenroomer are thanked for the electrical engineering involved with the construction of the setup. This work was supported by the Netherlands Foundation for Fundamental Research on Matter (FOM). The research of W.K. has been made possible by a fellowship of the Royal Netherlands Academy of Arts and Sciences (KNAW).

\section{REFERENCES}

1. J.R. Abelson, Appl. Phys. A 56, 493 (1993).

2. W.M.M. Kessels, A.H.M. Smets, D.C. Marra, E.S. Aydil, M.C.M. van de Sanden, Thin Solid Films 383, 154 (2001).

3. W.M.M. Kessels, J.P.M. Hoefnagels, P.J. van den Oever, Y. Barrell, M.C.M. van de Sanden, Surf. Sci. Lett. 547, 865 (2003).

4. J.W. Coburn and H.F. Winters, J. Appl. Phys. 50, 3189 (1979).

5. A. Von Keudell, T. Schwarz-Selinger, W. Jacob, Appl. Phys. Lett. 79, 676 (2000).

6. K.G. Tschersich, J. Appl. Phys. 87, 2565 (2000).

7. R. Anton, Th. Wiegner, W. Naumann, M. Liebman, Chr. Klein, Chr. Bradley, Rev. Sci. Instrum. 71, 1177 (2000).

8. R.W. Collins, A.S. Ferlauto, G.M. Ferreira, C. Chen, J. Koh, R.J. Koval, Y. Lee, J.M. Pearce, C.R. Wronski, Sol. Energy Mater. Sol. Cells 78, 143 (2003).

9. D.C. Marra, W.M.M. Kessels, M.C.M. van de Sanden, K. Kashefizadeh, E.S. Aydil, Surf. Sci. 530, 1 (2003).

10. I.M.P. Aarts, B. Hoex, A.H.M. Smets, R. Engeln, W.M.M. Kessels, M.C.M. van de Sanden, to be published in Appl. Phys. Lett. 84 (2004).

11. A.C.R. Pipino, J.P.M. Hoefnagels, N. Watanabe, J. Chem. Phys. 120, 2879 (2004).

12. I.M.P. Aarts, B. Hoex, J.J.H. Gielis, C.M. Leewis, A.H.M. Smets, R. Engeln, M. Nesládek, W.M.M. Kessels, M.C.M. van de Sanden, Mat. Res. Soc. Symp. Proc. 762, A19.8.1 (2003).

13. G.E. Jellison, Jr. and F.A. Modine, Appl. Phys. Lett. 69, 371 (1996).

14. R.W. Collins, J. Koh, A.S. Ferlauto, P.I. Rovira, Y. Lee, R.J. Koval, C.R. Wronski, Thin Solid Films 364, 129 (2000).

15. A.H.M. Smets, W.M.M. Kessels, M.C.M. van de Sanden, Appl. Phys. Lett. 82, 865 (2003).

16. T. Kamei and A. Matsuda, J. Vac. Sci. Technol. A 17, 113 (1999).

17. A. Fontcuberta i Morral and P. Roca i Cabarrocas, J. Non-Cryst. Solids 299, 196 (2002). 